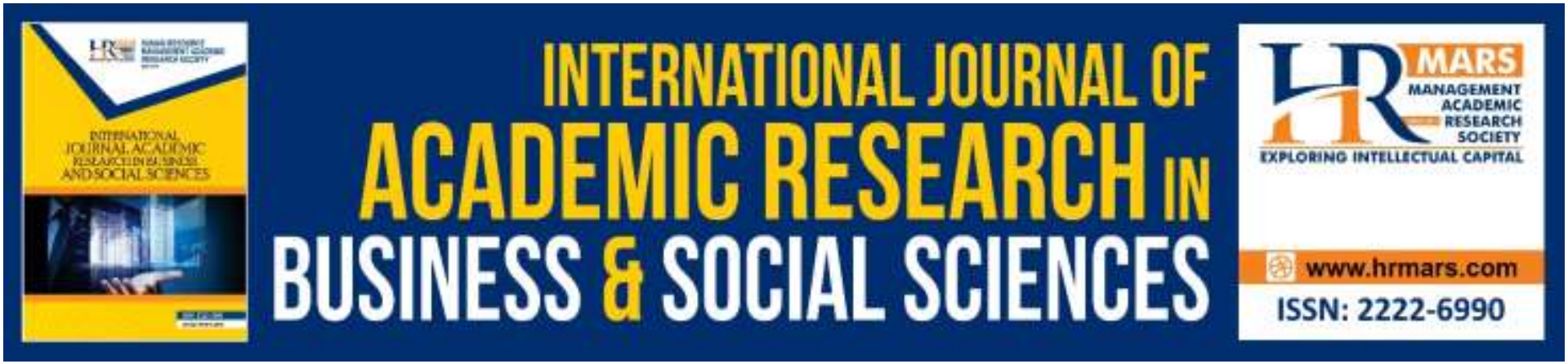

\title{
The School Experience of Malay Adolescent with Conduct Issues
}

Mohd Najmi Daud, Leigh Coombes, Sita Venkateswar, Kirsty Ross, Mohd Roslan Rosnon

To Link this Article: http://dx.doi.org/10.6007/IJARBSS/v9-i9/6306

DOI: $10.6007 /$ IJARBSS/v9-i9/6306

Received: 09 July 2019, Revised: 10 August 2019, Accepted: 30 August 2019

Published Online: 09 September 2019

In-Text Citation: (Daud, Coombes, Venkateswar, Ross, \& Rosnon, 2019)

To Cite this Article: Daud, M. N., Coombes, L., Venkateswar, S., Ross, K., \& Rosnon, M. R. (2019). The School Experience of Malay Adolescent with Conduct Issues. International Journal of Academic Research in Business and Social Sciences, 9(9), 389-402.

\section{Copyright: (c) 2019 The Author(s)}

Published by Human Resource Management Academic Research Society (www.hrmars.com)

This article is published under the Creative Commons Attribution (CC BY 4.0) license. Anyone may reproduce, distribute, translate and create derivative works of this article (for both commercial and non-commercial purposes), subject to full attribution to the original publication and authors. The full terms of this license may be seen at: http://creativecommons.org/licences/by/4.0/legalcode

\section{Vol. 9, No. 9, 2019, Pg. 389 - 402}

Full Terms \& Conditions of access and use can be found at http://hrmars.com/index.php/pages/detail/publication-ethics 


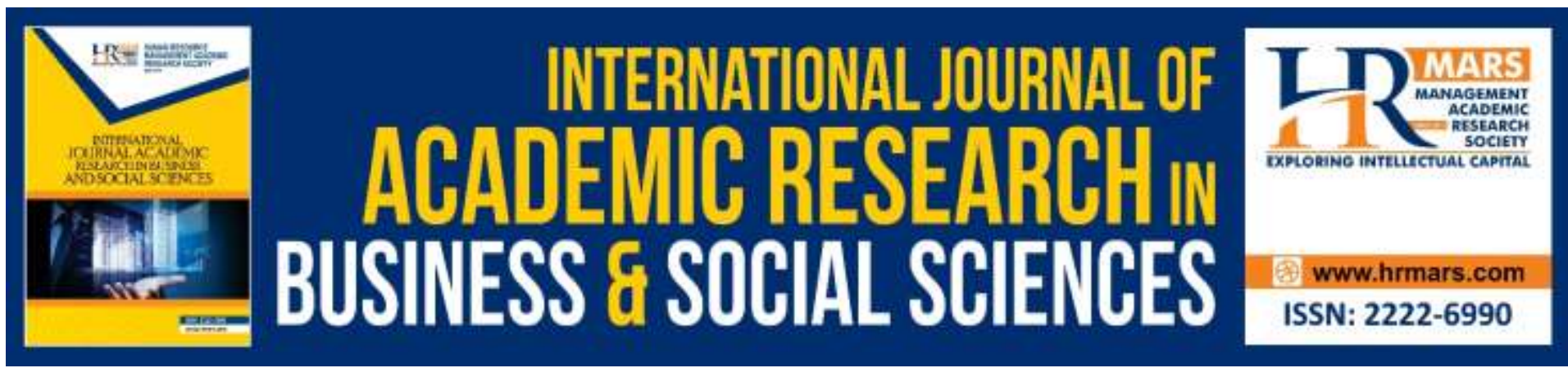

\title{
The School Experience of Malay Adolescent with Conduct Issues
}

\author{
Mohd Najmi Daud ${ }^{1}$, Leigh Coombes², Sita Venkateswar ${ }^{3}$, Kirsty \\ Ross $^{2}$, Mohd Roslan Rosnon ${ }^{4}$ \\ ${ }^{1}$ Department of Human Development and Family Studies, Faculty of Human Ecology, \\ Universiti Putra Malaysia, ${ }^{2}$ School of Psychology, Massey University, ${ }^{3}$ School of People, \\ Environment and Planning, Massey University, ${ }^{4}$ Department of Social and Development \\ Science, Faculty of Human Ecology, University Putra Malaysia
}

\begin{abstract}
This research is designed to explore how Malay adolescents who have been identified with conduct issues understand their school experiences. This research is a qualitative research, which utilized Interpretative Phenomenological Analysis (IPA) as an analysis method. Ten participants were recruited from a rehabilitation center for young offenders in Malaysia. Each participant completed at least two semi-structured interviews. The interviews were digitally recorded, transcribed, translated and analyzed for content. Through the emerging themes namely subject-oriented, issues pertaining to English as a medium of instruction, the nature of the school, inconsistency between personal interests and what the school has to offer, experiencing teaching and learning issues and individual differences related to school experiences, analysis suggest that participants felt disadvantaged by the school system. They felt that the education policies and school environment were irrelevant and unresponsive to their capabilities, needs, desires and interests. Thus, apart from benefiting people who work closely with these adolescents, this research provides the voice for the participant so that they feel heard.
\end{abstract}

Keyword: Malay Adolescents, Conduct Issues, Interpretative Phenomenological Analysis, School System, School Experiences.

\section{Introduction}

The formal education system in Malaysia has gone through various changes and transformation for decades. Whenever there are changes from one policy to another, the policy is said to be vague and difficult to be understood and internalized by the teachers, educators and students (Som \& Daud, 2007). This issue is due to the changes that take place are rapid and are designed to suit the Malaysia political system and government structure (Leong, 1992; Sua, 2012). As such, when there are changes in leadership at the state level, new ideas and amendments to the existing policy are anticipated. Thus, it is argued that the education system in Malaysia is like an experiment with students. This scenario is seen as a risk to the national education system as the system is not consistent and aligned with the 
initial objectives and philosophy of the national education system. The overemphasis on technical and managerial skills at the expense of the traditional academic subjects as a response to market demands indicates that the educational system in Malaysia is nothing more than acquiring specific skills and techniques with less emphasis on moral education (Hassan, 2005). This scenario affects those students who are unlikely able to cope with those subjects, which eventually leads to other problems in students such as high rates of school dropouts and conduct problems (Sua, 2012). It is evident that most of the adolescents with conduct issues are school dropout (Daud, 2017). But, how these adolescents make sense of their educational experiences remains elusive. Grounded on this argument, this research seeks to understand how adolescents who were identified as having conduct issues make sense of their school experiences. This research also attempts to investigate the possibilities to link the school experience and the experience of moral disengagements among adolescents in Malaysia.

\section{The Malaysian's Formal Education System}

The main objective of the National Education Policy during the early post-colonial period was to build national identity and to motivate racial integration in multi-racial Malaysia (Rozita, 2007). The education policy was also designed to respond to the national development agenda to build a just society and to narrow the educational gap and opportunity between ethnic groups (Ya-Fang, 2000; Rozita, 2007; Sua, 2012). Thus, the policy that focuses on the usage of Bahasa Malaysia as the primary language for school and the usage of English as the second language was put into force (Ali, Hamid \& Moni, 2011). In addition, the Malaysian government had tried to come out with an education system that could account for students with different attributes and abilities so that they had the opportunities to progress to higher education. Therefore, in 1962, the Malaysian government implemented the democratization of the education system (Sua, 2012) through which open certificate examination was introduced. This open certificate examination assures that students are allowed to choose their elective subjects of interest apart from several core subjects.

In recent years, the Malaysian Government launched the Education Development Plan 2013 - 2025 with a focus on student development. The plan has six core values to help the student to compete globally; knowledge, (critical) thinking skill, leadership skill, dual language skill, ethical and religious, and national identity (Ministry of Education Malaysia, 2012). This education plan which has its root in the Razak Report, 1956 and Education Ordinance, 1957 (Rozita, 2007) continues from the previous education plan with changes in its dynamic parallel to the current situation and condition. Nonetheless, the success of the implementation of the policy is arguable, in that the preferential policies currently used in Malaysian education make the majority population the beneficiaries instead of aiding the other minority population of the country (Ya-Fang, 2000), and it has somewhat contributed to the complexities of the development of a just society and the well-being of Malaysian.

Rosnon $(2014,2015)$ argued that while aiming at developing a national identity and nation building, the national education system is consistently Western-centric that positions the local culture and values at risk. This risky policy can be seen through the implementation of Dasar Memartabatkan Bahasa Malaysia Memperkukuh Bahasa Inggeris (Dignifying Bahasa Malaysia and Strengthening English Policy) which emphasises on mastering English in the process of exploring and acquiring knowledge in order to be a competitive nation nationally and globally (Ali, Hamid \& Moni, 2011). Various changes have been made in the National 
Education Policy to be in line with the requirements of the outlined language policies. For example, as part of the nation-building agenda, the National Education Philosophy is formulated to produce Malaysians who are knowledgeable, virtuous, responsible and capable of achieving well-being, and thus contribute to the betterment of the society and nation (Jamaluddin, 2011).

Due to an unclear message about its vision and mission as well as inconsistency in its implementation, the National Education Philosophy appears to be ambiguous to both students and educators (Som \& Daud, 2007; Rosnon, 2016; Rosnon, Talib \& Rahman, 2019). The inability to comprehend the essence of the philosophy has led students to reject the national education system, leading to a rise in social problems among students (Jamaluddin, 2011; Sua, 2012). Statistics shows that there is a decline in enrollment in mainstream schools (Department of Statistics Malaysia, 2018). The number of primary school students in the government and government aid schools showed a decline of $0.9 \%$ from 2683.8 thousand (2016) to 2,678.6 (2017) (Department of Statistics Malaysia, 2018). Meanwhile, the number of secondary school students in government and government aid schools decreased from 2,041.1 thousand (2016) to 2,005.9 thousand (2017) (Department of Statistics Malaysia, 2018). The decline in school enrolment rates underscored their rejection of the national education system.

In the meantime, the number of juvenile offenders in 2017 was 5.4 thousand, 5.1 thousand of them were boys, and the rest 0.3 thousand were girls (Department of Statistics Malaysia, 2018). It was found that juvenile crimes involving non-school going children was on the rise (The Strait Times, 2015). This statement is further supported by a research on the adolescents with conduct issues, which had found that majority or specifically 16 (57.1\%) out of 28 participants were school dropouts (Daud, 2017). The number of juvenile offenders cannot be underrated. This issue should be given serious attention by all parties such as school, family and society. Even though civic education, moral and religious subjects are taught in school, youth and students are still committing crimes and offences. Curiosity on the strength and limitations of the current education system from the perspectives of students themselves underpin the design of this research. The questions that are raised here are how do the students view the Malaysian education system from their own perspectives and how do they experience the system? These questions are essential because understanding the true purpose of education may keep students on the right pathway in moving towards a progressive nation as intended by the Malaysian government. Otherwise, students will not benefit from the education system, which eventually leads to other problems in students such as high rates of school dropouts and conduct problems (Sua, 2012).

\section{Methods}

\section{Research Design}

This research is a qualitative research, which utilized Interpretative Phenomenological Analysis (IPA) as a method of analysis. IPA was developed by Smith (1996) to explore the lived experiences of an individual in detail and to examine what the world is alike from the point of view of the participants. IPA is influenced by the phenomenological approach, which has its roots in Husserl's philosophical work, who suggested that in order to understand everyday experience, we need to develop a 'phenomenological attitude' toward a process by which we redirect our thoughts and immerse ourselves in the ways the world manifests itself (Shinebourne, 2011). Phenomenology aims for fresh, complex and rich descriptions of a 
phenomenon as it is concretely lived (Finlay, 2009). Husserl's phenomenological approach however has its limits, particularly with its focus on descriptive phenomenology (Smith, Flowers, \& Larkin, 2009) which involves the process of describing the lived experiences in the absence of meanings (Pringle, Drummond, McLafferty, \& Hendry, 2011). Therefore, Smith et al. (2009) argued that to understand other people's lived experiences, it is necessary to modify our inquiry. Thus, IPA engages with both the phenomenological and existential philosophy of Heidegger, Marleau-Ponty and Sartre, to understand that people are embodied and embedded in particular historical, social and cultural contexts (Shinebourne, 2011; Smith et al., 2009). IPA brings not the only description but drawing on hermeneutics. It enables researchers to facilitate the meaning of their experience through interpretation.

In IPA research, 'double hermeneutics' has become its critical dimension (Wagstaff \& Williams, 2014). Double hermeneutics refers to the process by which "the participant is trying to make sense of their personal and social world; the researcher is trying to make sense of the participant trying to make sense of their personal and social world" (Smith, 2004, p. 40). Specifically, in the present research, the 'double hermeneutic' was practised by linking those lived experiences of the Malay adolescents with the changes that happen due to globalisation processes. The third theoretical underpinning of Interpretive Phenomenological Analysis is idiography, which retains an in-depth focus and detailed examination of particular instances as well as a commitment to the "detailed finely textured analysis" of lived experiences (Smith et al., 2009). Idiography offers opportunities to learn about a particular individual or small group of cases and their response to specific contexts as well as connections between different aspects of the individual accounts. Shinebourne (2011) asserted that "the individual case can be used as a starting point in the process of analytic induction, affording an opportunity for working from the ground up by drawing together additional cases to move towards more general claims" (p. 47).

\section{Participants}

Ten $(\mathrm{N}=10)$ participants were recruited through purposive sampling from a rehabilitation center for young offenders in Malaysia. The inclusion criteria were Malay male, aged between 16 and 18 (Mean=17.3), with identified behavioral problems, able to read and communicate in Malay or English, willing to participate and share their experiences, attended school before their detention and have no psychological issues that may affect their participation. Out of ten participants, three were charged with rape, four were charged with theft, one was charged with drug related offences, one was charged with causing hurt and one was charged with house breaking. Apart from these charges, the participants also shared their experiences being involved in various other offences such as truancy, alcohol consumption and illegal road racing, but they have never been caught or charged by the relevant authorities for participating in those offences. While four participants reported that they remained at school until their detention, the other three participants shared that they had voluntarily dropped out of the school and three had been expelled from school for various misconducts. The mean age of the onset dropped out of school among participants was 15. Although the four participants who shared that they remained at school until their detention, their narrative account revealed that they did play truant frequently.

Analysis suggested that all participants had experienced various familial, social, and economic issues, which potentially affect their school experiences. As such, the parents of two participants were reported to have been divorced. One had experience of adoption. Three 
participants reported that they faced inter parental conflicts between their parents as they used to watch their parents fight with each other. Three participants asserted that they had family members who involved in crime. Other familial problems shared by the participants were having communication issues between family members. Concerning economics status, most participants reported that they had financial issue as their parents either unemployed or were working as unskilled laborers such as lorry driver, small-scale-farmer and performing multiple village jobs, which offer limited income. Their financial issue was further complicated by the fact that several of them live in urban area where higher living cost is expected. With regard to social life, almost all participants reported that they made friend with their peers and people older than them who had involved in crimes.

\section{Research Procedures}

The permission to conduct the present research was sought from Malaysian Community Welfare Department through the Economic Planning Unit (EPU). The ethical approval was granted by the Massey University Human Ethic Committee (MUHEC) (HEC: Southern A Application - 13/23). The ethical considerations include privacy and confidentiality of the participants' identities and data acquired from them, interview procedures, data management, security measures for both the researcher and the participants, and research fund. As for recruitment procedures, the authorities of identified rehabilitation centers were responsible selecting potential participants. Voluntary participation was maintained. Prior to the research, each participant was informed about the nature of the research process and their rights should they decide to participate in the research. In this research, the authority for consent was the delegation of the rehabilitation centre for those inmates who agree to participate. Each participant was requested to complete at least two semi-structured interviews. The duration of the interview session ranged from 50-60 minutes per session. An interview schedule was used to guide the interview. The participants were asked to share their school experiences through open ended questions such as "can you tell me about your school experience?" and "How do you feel about going to school?" All interviews were digitally recorded, transcribed, reviewed and verified for accuracy by the participants themselves, translated into English and analysed for contents.

The challenges we faced in understanding their school experiences were recognizing the differences between our prior knowledge position as we developed the questions and during the interviews. We had areas that we wanted to explore based on our preconceived insider knowledge of the Malaysian education systems and the local cultures and values. In this sense, we had a tendency to frame participants' experiences within the context that we were familiar with, which reflect our knowledge about the Malaysian education system and the participants' experiences. To manage this researcher bias, we had frequent discussions among all researchers to locate the experience of participants in their understanding so that we could open up more space for the participants to talk about their experiences in their unique context of their school experiences. We engaged in the approach that allowed the participants to set the tone and pace of the interview. They had opportunities to talk about their lives experiences using their own words, perceptions and understandings.

\section{Analysis}

The analysis followed the seven analysis stages as suggested by Smith et al. (2009), 1) reading and re-reading, 2) initial noting, 3) developing emergent themes, 4) searching connections 
across emergent themes, 5) moving to the next case, 6) looking for patterns across cases and 7) taking the interpretations to a deeper level. The analysis began with the researcher carefully reading and re-reading each transcript to become familiar with the data and to generate a general perspective about the data. Researchers wrote some relevant notes in the margins while reading the transcripts as they explored the content. Then, the researcher went back to the original transcripts to extract all the significant statements that were relevant to the research objectives and research questions, to understand how Malay adolescents with conduct issues make sense of their lived experiences in response to the changing context. All the extracted statements were then organised into boxes alongside the researcher comments, reflections, the initial idea of themes and possible emerging superordinate and subordinate themes, which were consistent with step three of IPA analysis, the development of emergent themes. At this stage, the analysis process was conducted case by case. In keeping with IPA's idiographic commitment, each case was considered and examined in its own terms (Smith et al., 2009). The emerging themes in each case were examined and clustered together with the remaining cases, according to their conceptual similarities. I then started clustering the themes into more precise superordinate and subordinate themes also noting idiosyncratic instances. The final superordinate and subordinate themes were then described and interpreted in a more meaningful way according to research objectives.

\section{Results}

Before analysing the participants understanding, it may of some help to note that these adolescents attended school with the education system that emphasised the importance of science and technical based subjects to meet the needs of the country in becoming a developed nation by the year 2020. It has been argued that the strong preference of government for science and technical subjects narrows the chances of students who are inclined to art and vocational studies (Sua, 2012). In this study it appears that through the emerging themes i.e. subject oriented, issues pertaining to English as medium of instruction, the nature of the school, inconsistency between personal interest and what the school has to offer, experiencing teaching and learning issues, and individual differences related to school experience, students, who were not able to cope with the demands, simply gave up and chose other directions. Also, those themes demonstrate issues connecting the education system and the emerging conduct issues among the participants. The analysis highlights the problems that education policies had on the participants as they felt the system did not meet their needs, and they felt they did not belong. The way the school system operated meant that some of the students felt like they did not have the intellectual capacity or the confidence they required to achieve, and some resisted the compulsory requirement to participate in cocurricular activities.

\section{Subject Oriented}

In relation to the strong preference of government for science and technical subjects, the participants highlighted the difficulties they had in completing the subjects taught at school. The participants talked about their concern with several subjects that demotivated them to remain in school. For several of them, English and mathematics were challenging, especially as they progressed through to secondary school, where they had no choice over the subjects they studied. The challenges they faced increased the stress in their lives: 
"I was interested in math, BM (Malay language), (and) BI (English language) but I did not really like English, but I have to." (Arif, p. 5)

"The subjects that I hate the most were mathematics and English because mathematics gave me a headache, all the calculations made me feel uneasy." (Madi, p. 25).

It was not only English and mathematics that were cited as difficult. Tapa stated that Islamic studies and the Malay language also made him uninterested in continuing his education.

"Some subjects like mathematics, Islamic studies, and Malay made me feel sleepy. I was

not interested in school since I was in form 1." (Tapa, p. 11)

Nuar mentioned that he does not like writing. All subjects in school placed value on writing over other skills. He felt that the school did not offer any opportunity for him to show and to polish his personal strengths. He was particularly interested in subjects that emphasise technical skills.

"I love vocational courses, but I don't like writing." (Nuar, p. 34)

It appears that students who were not able to cope with the demands, simply gave up and chose other directions.

\section{Issues Pertaining to English as Medium of Instruction}

One of the important issues with regards to the Malaysian education policy is the introduction of Teaching and Learning Mathematics and Science in English (ETeMS), which was introduced in 2003 by the Malaysian government (Chan \& Helen, 2006; Lai \& Ishak, 2012). The introduction of this policy was linked to globalisation, which is dominated by English as a medium of instruction. However, this policy was reversed in 2012 due to some limitations such as only small percentage of teachers who fully used English to teach Mathematics and Science and the proficiency of the students in the two subjects had been on a steady decline (Lai \& Ishak, 2012). Given that, for one participant, it was English as a medium of instruction that was a problem rather than particular subject areas. While he displayed proficiency in English as a subject, learning other subjects through the medium of English was a challenge and he lost motivation,

"I could understand English well, (unfortunately) some terminologies were very strange to me. I couldn't understand them. Because of that, I started to feel unmotivated to continue my schooling." (Ajam, p. 17)

Listening to the perspectives of the participants supports the claim that the decline in academic achievement among school pupils is associated with the introduction of English as a medium of instruction for mathematics and science subjects (Lai \& Ishak, 2012).

\section{The Nature of the School}

The participants tended to associate their lack of success at school with the nature of the school. For them, the school environment and the school system were not good enough to convince them to stay at school any longer. There was no excitement offered by the school. Their concerns included the general school environment, duration of the school times, unattractive school programs, unavailability of the teachers and personal bullying. For example, Ajam felt his school was not a conducive place to study. His school was well known among the local community for its history of serious behavioural problems, and its proximity to the amenities that are visible as a distraction from school life. 
"(I had a problem with) the school environment. I'm not able to explain that and as you know, I study at XXX school, so, it's normal (as it is well known or labelled as a problematic school by the society)." (Ajam, p. 17)

The participants also expressed their feeling about learning related activities that did not meet their interests or desires. Studying was perceived as not a pleasurable or enjoyable activity.

"I didn't want to mingle with good friends because they were always with their books and studies. What a bore (activities)." (Youp, p. 26)

"I felt bored being in school." (Tapa, p. 11).

The participants responded to their feelings of boredom by becoming truant and instead began to seek more exciting activities that the school did not provide:

"Sometimes, I played truant from class, hung out at the school canteen, if the teacher looked for me, I would run away. If I felt too bored being at school, I would skip school." (Youp, p. 2)

Without the teachers being responsive to his needs, Youp perceived that the school system was hindering him from socialising with his friends.

"I didn't enjoy being at school. It was boring. I need to study at all times. I had less time to talk to other people." (Youp, p. 2)

Nuar reacted to extended days at school, referring to a day a week when all students in his school had to stay until late in the afternoon to participate in extra co-curriculum activities.

"Yes, always (played truant). Every Wednesday was a co-curriculum day. We had to stay at school from morning until late in the afternoon. To me, it was unbearable." (Nuar, p. 11)

Both Nuar and Mizi expressed a lack of attention from teachers as a problem that reinforced the earlier idea of having no connection with adults that should have cared for them.

"The teacher also didn't care about us." (Nuar, p. 27)

"At school, the teachers always went out (for other programs)." (Mizi, p. 14)

Usop who had suffered bullying because he didn't meet the socially accepted dress code norms of his peers, was also isolated from his peers as a result of poverty. This stopped him from attending classes and despite telling his teacher it seems that this issue was not addressed.

"Whilst I was in the prayer room (at my school), I haven't had any food, but it was ok provided that I didn't need to meet my friends. Because of that, I had informed the teacher, I would not go into the class." (Usop, p. 7)

\section{Inconsistency between Personal Interests and What the School Has to Offer}

The participants in this study became increasingly disinterested in attending to the requirements of school and started turning away from school to have their interests met.

"I simply don't have passion to study." (Ajam, p. 20)

"I was not interested in school. I was interested to listen to the lesson only, but I was not interested to write." (Tapa, p. 6)

"Starting from secondary school, I had never done homework. I was really not interested in doing it." (Nuar, p. 27)

"I felt like doing something else, such as going to, cc, playing games. I'm not really interested in school. I am interested in things that are more technical." (Mizi, p. 14) 
"Yes, sometimes I did think about it, I felt like going back to school. But, when I was with my friends, I thought nothing." (Sidi, p. 15)

As for Dino, he did not necessarily dislike school but his friendship group became more interesting for him.

"Actually, I was interested in school, but I was more interested in hanging out with my friends." (Dino, p. 17)

\section{Experiencing Teaching and Learning Issues}

Several participants talked about experiencing difficulties learning, and experienced their failure as an individual deficit.

"I am a slow learner, nothing went into my mind during the class lessons." (Madi, p. 25) "I like to study, but I am not good at it. I am stupid... I could not follow the lessons in class. It (also) depended on who taught the subject." (Usop, p. 12)

"I don't know, I could not accept the lessons." (Sidi, p. 15)

\section{Individual Differences Related to School Experiences}

The participants also made sense of their school experiences through their individual differences in learning. For instance, Dino perceived that studying was a complicated and long process. He found it was difficult for him to follow the normal processes of gaining knowledge through studying at school. He preferred a shorter way of learning which was by engaging in crime. Dino believed that by engaging in crime, the progress of gaining knowledge would be faster and more effective.

"It is not when you commit crimes. You don't need to attend school, you can do it straight away. So fast. I had learnt a lot while I was committing crimes." (Dino, p. 25)

Mizi was not interested in the ways schooling is offered as he was more capable at technical tasks, which he stated were necessary to survival.

"If you are not good at school, you must be good at technical things." (Mizi, p. 15)

While Usop perceived school is the best place to acquire knowledge, the environment itself provided him with little protection. His turn to criminal activity provided him with the ability to learn the skills required to protect himself.

"To me, I cannot get the knowledge from anywhere except school. My mom has said that, it was normal (to be bullied) at school. You should not hope that people would spoil you." (Usop, p. 8)

"they (my criminal friends) had advised me that, if I wanted to be a gangster, I must join their group. I was convinced to join them, I would like to be a stronger person, and I did not want to look weak anymore. I didn't want to see people take advantage of my weaknesses" (Usop, p.10).

\section{Discussion and Conclusion}

This research seeks to understand how the Malay adolescents with conduct issues make sense of their school experiences. Consistent with the objective of the present research, the IPA methodology was utilised to enable the systematic exploration and contextualization of the participants' school experiences. Being an insider provided the researcher with access to the participants' stories that other researchers may not have had, and gave us a level of insight into the Malay adolescents' school experiences. Despite that, the participants were encouraged to locate their experiences in their understandings. They were allowed to set the 
tone and pace of the interview. While the researcher prompted questions, the researcher was able to follow the stories the participants chose to share.

The stories shared by the participants showed that the school was not the place that the participants enjoy. They described that the education policies and school environment were irrelevant and unresponsive to their capabilities, needs, desires and interests. They felt that the school failed to provide them with any excitement. This finding clarifies the previous studies, which had highlighted the ambiguity experienced by the adolescents about the wisdom behind the changes that have been made in the Malaysian education system (Som \& Daud, 2007; Rosnon, 2016). In particular, the participants were concerned with the subjects being taught in school, whereby some participants described that they easily became bored in Islamic studies and Malay language classes. Several others found that English and Mathematics were very challenging. They argued that these subjects demotivated them to remain in school. Some participants raised the issue of having difficulties following the lessons in school, either because English had become the medium of instruction or they felt like they did not have the intellectual capacity that made them feel incompetent within the education system. They felt that the learning process at school was such a challenging undertaking. Thus, the participants felt disadvantaged by the school system. All these issues had driven them to engage in truancy, which potentially leads to more serious behavioural issues.

In addition, the school that is mandated to shape the lives of the participants through the dissemination of good values (Islamic values), knowledge and skills was no longer active in the participants' life endeavours. Although the school did attempt to instil Islamic values through subjects like Islamic studies and moral education, there were issues with the teaching and learning approaches as some participants were unable to grasp the knowledge and to practice it in their lives. As a consequence, the issue with the school system has led to a rise in social problem among adolescents as they preferred to leave the school (Daud, 2017; Jamaluddin, 2011; Sua, 2012)

Given the limitations highlighted by the participants, it would offer some help if the government and all relevant parties could come up with creative psychological mechanisms that may contribute toward improving the understanding of philosophy behind the Malaysian education system among these 'disadvantaged' students and for them to value the knowledge taught at school in their lived experiences. In addition, the consistency of the policy implementation, without unnecessary changes within a reasonable timeframe would add value to the process of nation building through the education system. We argue that a realistic and practical timeline should be set and followed accordingly with regards to any changes made to the existing policies. Also, in proposing and implementing new educational policy, it is important not to focus solely on the governmental aspirations but also the voice of the students of various capabilities and needs. Their voice should be attended attentively so that the education system can be seen as relevant and responsive to both the needs of the students as well as the government aspirations.

In sum, the present findings would contribute to an effort to revisit the existing education system in Malaysia in several ways. Firstly, the findings of this research may underpin the consideration in widening the concept of inclusivity in the education system by taking into account the diversity in learning competency and capabilities as well as the different interests and desires of the students. Secondly, the story and experiences shared by the participants suggest that apart from the inclusivity, a different option of the education system is worth to be proposed. This measure is essential so that these adolescents can remain in the Malaysian 
education system as they have the opportunity to learn in a way that consistent with their need, desire and capabilities. Finally, we conclude that the voice of the adolescents themselves should be regarded as one of the crucial substances that contributes to the development of a more responsive educational policy in Malaysia. We believe that if the measures as mentioned earlier could be incorporated in planning and implementing the education system in Malaysia, the number of dropout among adolescents could be reduced. Also, as an implication, they potentially reduce the number of conduct issues among adolescents in Malaysia.

\section{Acknowledgement}

This research was supported by Universiti Putra Malaysia (UPM), Massey University, New Zealand, Ministry of Education Malaysia and Department of Social Welfare Malaysia.

\section{Corresponding Author}

Mohd Najmi Daud, Department of Human Development and Family Studies, Faculty of Human Ecology, University Putra Malaysia. Email: najmi@upm.edu.my

\section{References}

Ali, N. L., Hamid, O., \& Moni, K. (2011). English in primary education in Malaysia: Policies, outcomes and stakeholders' lived experiences. Journal Current Issues in Language Planning, 12(2), 147-166.

Chan, S. H., \& Helen, T. (2008). English for mathematics and Science: Current Malaysian language-in-education policies and practices. Language and Education, 20(4), 306-321.

Daud, M. N. (2017). Globalization in the Malaysian context: The experience of Malay adolescents with 'conduct disorders' (Unpublished doctoral dissertation). Massey University, Palmerston North, New Zealand.

Department of Statistics Malaysia (2018). Children statistics publication, Malaysia 2018. Retrieved from

https://www.dosm.gov.my/v1/index.php?r=column/pdfPrev\&id=RWsxR3RwRVhDRIJkK1 BLalgrMGRIQT09

Finlay, L. (2009). Debating phenomenological research methods. Phenomenology \& Practice, $3(1), 6-25$.

Hassan, K. (2005). Challenges of globalization: Setting the Muslim mindset in Malaysia. Policy Perspective, 2(1), 33-54.

Lai, F. Y., \& Ishak, M. S. A. (2012). Framing controversy over language policy in Malaysia: The coverage of PPSMI reversal (teaching of mathematics and science in English) by Malaysian newspapers. Asian Journal of Communication, 22(5), 449-473.

Leong, H. K. (1992). Dynamics of policy-making in Malaysia: The formulation of the New Economic Policy and the National Development Policy. Asian Journal of Public Administration, 14 (2), 204-227.

Som, M. H., \& Megat Daud, M. A. K. (2007). Globalisasi dan cabaran pendidikan di Malaysia. Masalah Pendidikan, 31(1), 91-101.

Ministry of Education Malaysia (2012). Pelan Pembangunan Pendidikan Malaysia 2013-2025. Putrajaya, Malaysia: Author. 
Jamaluddin, M. K. A. (2011). Sistem pendidikan di Malaysia: Dasar, cabaran, dan pelaksanaan ke arah perpaduan nasional. SOSIOHUMANIKA: Jurnal Pendidikan Sains Sosial dan Kemanusiaan, 4 (1), 33-48.

Pringle, J., Drummond, J., McLafferty, E., \& Hendry, C. (2011). Interpretative Phenomenological Analysis: A discussion and critique. Nurse Researcher, 18(3), 20-24.

Rosnon, M. R. (2014). Challenges on the Orang Asli's rights in mainstream education in Malaysia: An overview. Malaysian Journal on Human Rights, 57-72.

Rosnon, M. R. (2015, April). Orang asli education policy: Equity and recognition. Paper presented at the International Conference on Access to Justice for Indigenous Peoples: An Inclusive and Integrated Approach to Human Rights, Kuala Lumpur, Malaysia.

Rosnon, M. R. (2016). Indigenous education policy in Malaysia: A discussion of normalization in schooling. Journal of Education and Social Sciences, 4, 25-32.

Rosnon, M. R., Abu Talib, M., \& Wan Abdul Rahman, N. A. F. (2019). Self-determination of indigenous education policies in Australia: The case of the aboriginal people and Torres Strait Islander people. Pertanika Journal of Social Sciences \& Humanities. 27(S1), 267-284.

Rozita, I. (2007). Multiculturalism and education in Malaysia. Culture and Religion: An Interdisciplinary Journal, 8(2), 155-167.

Shinebourne, P. (2011). The theoretical underpinnings of Interpretative Phenomenological Analysis (IPA). Existential Analysis, 22(1), 16-32.

Smith, J. A. (1996). Beyond the divide between cognition and discourse: Using interpretative phenomenological analysis in health psychology. Psychology and Health, 11(2), 261-271.

Smith, J. A. (2004). Reflecting on the development of Interpretative Phenomenological Analysis and its contribution to qualitative research in psychology. Qualitative Research in Psychology, 1, 39-54.

Smith, J. A., Flowers, P., \& Larkin, M. (2009). Interpretative Phenomenological Analysis. London: SAGE Publication.

Sua, T. Y. (2012). Democratization of secondary education in Malaysia: Emerging problems and challenges of educational reform. International Journal of Educational Development, 32 (1), 53-64.

The Strait Times (2015, March 30). Juvenile crime among school dropouts on the rise in Malaysia. Retrived from https://www.straitstimes.com/asia/se-asia/juvenile-crimeamong-school-dropouts-on-the-rise-in-malaysia

Wagstaff, C., \& Williams, B. (2014). Specific design features of an Interpretative Phenomenological Analysis study. Nurse Researcher, 21(3), 8-12.

Ya-Fang, C. (2000). Educational opportunities for Chinese in Malaysia. Educational Research, 33, 585-591. 